\title{
Atividades Investigativas na Educação Científica: Dimensões e Perspectivas em Diálogos com o ENCI
}

\section{Investigative Activities in Scientific Education: Dimensions and Perspectives of Inquiry-Based Science Teaching}

\author{
Roseline Beatriz Strieder ${ }^{(1)}$ Brasil \\ Graciella Watanabe ${ }^{\mathbb{D}}$ Brasil
}

As atividades investigativas têm sido recomendadas no contexto educacional há longa data, como pode ser constatado em publicações da área de Ensino de Ciências, documentos oficiais e materiais didáticos. Ao analisarmos essas produções, percebemos que há diferentes pressupostos, propostas de atividades e recomendações que nem sempre estão explícitos, dificultando uma compreensão mais crítica sobre o assunto e a própria elaboração e desenvolvimento de práticas escolares. Diante disso, neste trabalho discutimos uma sistematização das diferentes perspectivas de atividades investigativas, com ênfase nos objetivos formativos e visões de ciências, com a intenção de melhor compreender essa abordagem e contribuir para a elaboração e desenvolvimento de novas pesquisas e práticas escolares. Para tanto, realizamos uma pesquisa de cunho bibliográfico, mais especificamente, uma análise da produção da área de ensino de ciências, por meio dos artigos publicados em revistas. Dentre os resultados, além de uma descrição da produção científica no que se refere aos objetivos das pesquisas, níveis de ensino e resultados encontrados, destacamos que as propostas analisadas apresentam diferentes objetivos formativos e visões de ciências, algumas pouco críticas e que podem veicular imagens deformadas sobre a ciência. Defendemos, nesse contexto, que à medida que tais atividades são pensadas no âmbito das questões pedagógicas propostas pelo Ensino de Ciências por Investigação, aspectos educacionais se tornam mais claros e conduzem a perspectivas processuais e reflexivas sobre as ciências.

Palavras-chave: Atividades Investigativas; Educação Científica; Revisão Sistemática de Literatura.

Investigative activities have long been recommended in the educational context, as can be seen in Science Education publications, curricular guidelines and teaching materials. By analyzing these productions, we note that there are different assumptions, proposals for activities and recommendations, which are not always explicit. This hinders a more critically understanding on the subject and the very elaboration and development of school practices. Therefore, in this paper, we discuss a systematization of the different perspectives of investigative activities, with emphasis on the formative objectives and visions of science, to better understand this approach and contribute 
to the elaboration and development of new research studies and school practices. We conducted a bibliographic research, more specifically, an analysis of the productions in science education, through articles published in journals. Among the results, besides a description of the scientific production regarding the objectives of the researches, levels of teaching and results found, we highlight that the analyzed proposals present different formative objectives and visions of science, some of which are not critical and that can lead to deformed visions of science. In this context, we argue that as such activities are thought within the pedagogical issues proposed by Science Teaching through Investigation, the educational aspects become clearer and promote procedural and reflexive perspectives on the sciences.

Keywords: Scientific Literacy; Teaching Conceptions; Biology Teaching.

\section{Introdução}

A realização de atividades investigativas é defendida desde meados do século XIX no âmbito da educação científica (Abd-El-Khalick et al., 2004; Couso, 2014), mas tem recebido destaque nas pesquisas em ensino de ciências nos últimos anos. No Brasil, esse debate vem sendo substanciado por temas como os apresentados no "Encontro de Ensino por Investigação", realizado na Universidade de São Paulo em 2017. Esse evento retrata que essa abordagem pode ser considerada uma temática relevante no contexto educacional brasileiro, visto que contou com 500 participantes inscritos e 350 trabalhos aceitos para apresentação. Além disso, a própria publicação do número especial sobre Ensino de Ciências por Investigação (ENCI) na Revista Brasileira de Pesquisa em Educação em Ciências (RBPEC) em 2018 indica esse interesse.

No contexto das produções sobre o assunto, muitos trabalhos enfatizam a diversidade de significados e perspectivas relacionadas a essa abordagem e suas contribuições para a formação de cidadãos (Abd-El-Khalick et al., 2004; Anderson, 2002; Barrow, 2006; Couso, 2014; Deboer, 2006; Hodson, 1994; Munford, \& Lima, 2007; Reyes-Cárdenas, \& Padilla, 2012; Zômpero, \& Laburú, 2011).

Zômpero e Laburú (2011), afirmam que a atividade investigativa esteve presente no contexto do ensino de ciências em diferentes épocas e com diferentes propósitos; vinculada, por exemplo, ao desenvolvimento de habilidades científicas, no final do século XIX e meados do XX; ao entendimento de problemas sociais, como o aquecimento global, a poluição, etc. nas décadas de 70 e 80 do século XX; e, atualmente, com vistas ao "desenvolvimento de habilidades cognitivas nos alunos, a realização de procedimentos como elaboração de hipóteses, anotação e análise de dados e o desenvolvimento da capacidade de argumentação" (Zômpero, \& Laburú, 2011, p. 73). Nessa perspectiva, os autores destacam o caráter inconclusivo dessa abordagem, mas que "possibilita o aprimoramento do raciocínio e das habilidades cognitivas dos alunos, e também a cooperação entre eles, além de possibilitar que compreendam a natureza do trabalho científico" (Zômpero, \& Laburú, 2011, p. 68) . 
Essas perspectivas também são apontadas no trabalho de Barrow (2006), que analisa a presença das atividades investigativas no contexto do ensino de ciências norteamericano e afirma que não há uma definição clara sobre o que significam. Para o autor, nesse contexto, há três perspectivas distintas: as centradas no desenvolvimento de capacidades de investigação, como a elaboração de perguntas ou a realização de experimentos para comprovar hipóteses; as que buscam a compreensão, por parte dos alunos, do processo de construção da ciência, ou seja, como trabalham os cientistas e elementos relacionados à natureza da ciências; e, por fim, as que visam o aprendizado de conceitos científicos e dos processos de investigação.

De acordo com Couso (2014), cada abordagem de ensino e aprendizagem por investigação associa-se a determinadas perspectivas de ensino e de ciência e, em função disso, para a autora, deveríamos, enquanto pesquisadores e educadores, nos preocupar com essas visões, pois algumas vezes, podem perpetuar concepções ingênuas. Tais perspectivas ingênuas, segundo Couso, são as que: (i) reduzem as aulas de ciências ao desenvolvimento de investigações, mas não contribuem para que os alunos aprendam, de fato, a investigar; (ii) defendem que a maior contribuição das atividades de investigação é a de envolver os alunos e motivá-los para aprender ciências; (iii) entendem que o papel do professor é, somente, o de facilitar ou orientar os alunos no processo, não compreendendo a complexidade dessa ação; e, associado a todos esses; (iv) levam a uma compreensão equivocada da ciência por centrarem na realização de investigações e deixarem para um segundo plano outras questões importantes na ciência, como os modelos e a argumentação.

Em diálogo com essa diversidade de perspectivas apontadas por Zômpero e Laburú (2011), Barrow (2006) e Couso (2014) e reconhecendo que todas estão presentes no contexto atual da educação científica e da pesquisa em ensino de ciências, ainda que implicitamente, apontamos a necessidade de essas temáticas serem mais bem compreendidas para que tenhamos uma clareza maior sobre as potencialidades e limitações das atividades investigativas para formação dos estudantes. Essa diversidade, ainda que interessante, por ampliar o espectro de possibilidades de inserção das atividades investigativas nos currículos escolares, precisa ser caracterizada, em especial, porque a ausência de clareza dificulta a efetividade das propostas. Como destaca Deboer (2006), apesar de existirem essas possibilidades, vários pesquisadores têm relatado insucessos, os quais, para ele, estão associados a uma ausência de clareza quanto aos objetivos almejados com as atividades investigativas.

Diante disso, ainda que muitas pesquisas têm retratado a polissemia de perspectivas em torno da realização de atividades investigativas no ensino de ciências, não encontramos trabalhos que realizam uma análise sistemática da literatura da área. É com essa preocupação que a presente pesquisa foi desenvolvida e centrou-se na seguinte questão: Quais objetivos formativos e visões de ciência comparecem em produções atuais da área de ensino de ciências centradas em atividades investigativas? Na busca por compreender tal questionamento tratamos duas dimensões de análise: objetivos 
formativos e visões de ciência. A dimensão dos objetivos formativos abarca os propósitos educacionais defendidos e almejados no âmbito das propostas, associando-se a distintas perspectivas educacionais. A dimensão das visões de ciência está relacionada a questões sobre o processo de construção do conhecimento científico e seu papel na sociedade; diz respeito, portanto, às perspectivas de ciência explícitas ou implícitas nas atividades e possui relações com os conhecimentos a serem construídos em atividades desse tipo.

Tais dimensões permeiam o debate pretendido com este trabalho e que defende o ENCI como norteador das propostas de atividades investigativas, clarificando objetivos e sentidos negociados no processo de ações pedagógicas entre professores e alunos. Assim, este trabalho apresenta reflexões em torno das produções centradas em atividades investigativas e defende que as mesmas devem ser entendidas como práticas que conduzem a percepções da ciência que perpassam tanto aspectos da produção do saber da ciência como de suas dimensões culturais e sociais.

Considerando que não seria possível uma análise sistemática de toda a produção da área, optamos por selecionar artigos publicados em revistas qualificadas de dois contextos distintos, da Espanha e do Brasil. Ambos possuem uma preocupação explícita com as atividades investigativas nos documentos oficiais e, além disso, vários trabalhos publicados sobre o assunto. Assim, neste artigo analisamos as produções centradas nessa temática e publicadas em periódicos de ensino de ciências nesses dois países com o objetivo de caracterizar aspectos formativos e visões de ciências presentes nesses trabalhos em consonância ou não ao ENCI.

Iniciamos este estudo com uma breve revisão histórica sobre a inserção de atividades investigativas no ensino de ciências e pesquisas que discutem a polissemia dessa abordagem, dando ênfase às preocupações que são debatidas no contexto do ENCI. Essa revisão é importante para compreendermos quais as diferentes perspectivas apontadas na literatura e sua relação com distintos momentos históricos. Em seguida, apresentamos a metodologia empregada nesta investigação, os resultados e considerações a respeito dos objetivos formativos e visões de ciência balizadoras dos trabalhos analisados. Com isso, pretendemos contribuir para o universo de pesquisas da área, apontando questões ou aspectos privilegiados em estudos sobre o assunto.

\section{Atividades de investigação na educação científica: breve histórico e polissemia}

Aulas de ciências de cunho investigativo são defendidas desde meados do século XIX, quando as disciplinas de ciências passaram a integrar os currículos escolares (Barrow, 2006; Deboer, 2006). Dentre os primeiros a defender um ensino nessa perspectiva, encontra-se John Dewey, para quem os conteúdos escolares deveriam estar diretamente relacionados a problemas próximos dos alunos e serem coerentes com seu nível cognitivo; pois, com isso, seria possível contribuir para que os alunos se tornassem aprendizes ativos, que buscam suas próprias respostas (Barrow, 2006; Andrade, 2011).

Apesar disso, de acordo com Deboer (2006), foi no período pós-guerra que a realização 
de investigações recebeu mais destaque, pois se passou a almejar um ensino que proporcionasse mais autonomia e liberdade ao aluno, que deveria participar mais do processo de aquisição dos conhecimentos. Nessa época, foram desenvolvidos vários projetos que defendiam a realização de atividades de investigação, a exemplo do Synthesis, Project 2061, Biological Sciences Curriculum Study (BSCS), Physical Science Study Committee (PSSC), Science Curriculum Study (SCIS) e Elementary Science Study (ESS) (Barrow, 2006; Rodrigues, \& Borges, 2008). Cabe destacar que, como afirma Krasilchik (1987), nessa época, o lema era "aprender fazendo"; as atividades de ensino-aprendizagem deveriam ser desenvolvidas segundo a racionalidade da atividade científica e tinham a finalidade de contribuir com a formação de futuros cientistas. As propostas educativas que surgiram nesse período, portanto, procuraram possibilitar aos estudantes o acesso às verdades científicas, a vivência do método científico e o desenvolvimento de uma maneira científica de pensar e agir.

Dentre as publicações do século XXI, destacamos os relatórios do Conselho Nacional de Investigação dos Estados Unidos da América (NCR, 2000), da União Europeia (Rocard, 2007) e da Nuffield Foundation (Osborne, \& Dillon, 2008). O primeiro, intitulado "Inquiry and the National Science Education Standards" (NCR, 2000) apresenta discussões sobre o que se entende por investigação e por atividades investigativas, como essas atividades podem ser avaliadas e experiências desenvolvidas nos Estados Unidos, na perspectiva de apresentar subsídios para introduzir essa abordagem nas aulas de ciências. Nesse documento, é assumido que essa abordagem pode contribuir para que os alunos entendam conceitos de ciências, sobre investigação científica e desenvolvam habilidades para realizar investigações científicas. O documento da União Europeia, intitulado "Science Education now. A renewed pedagogy for the future of Europe" (Rocard, 2007) propõe que o ensino de ciências deveria ocorrer mediante a investigação, pois ela contribui, dentre outras coisas para motivar os alunos na aprendizagem em ciência. Em função disso, nesse Relatório, comparecem recomendações para efetivar essa abordagem e exemplos de alguns projetos que podem servir de inspiração/orientação, como o Pollen (desenvolvido em vários países da Europa) e o Sinus-Transfer (desenvolvido em escolas da Alemanha). O terceiro documento, intitulado "Science Education in Europe: Critical Reflections" (Osborne, \& Dillon, 2008) resulta de seminários realizados com educadores de 9 países da União Europeia com a intenção de levantar e discutir semelhanças e diferenças, problemas e possíveis soluções para o ensino de ciências nesses países. Nesse relatório, os autores destacam que, diante do contexto atual, o foco não deve ser a formação de uma nova geração de cientistas; é preciso contribuir para que a população tenha condições de se envolver com questões sociocientíficas e isso requer, além de conhecimentos científicos, compreender como a ciência funciona, o que, por sua vez, implica na realização de investigações científicas.

Também, têm merecido destaque os seminários internacionais realizados sobre o assunto e a publicação organizada por Flick e Lederman (2006), que apresenta uma série de textos, produzidos por diferentes pesquisadores, com a preocupação de esclarecer 
questões relacionadas ao ensino por investigação e ao ensino sobre a natureza da ciência, considerados dois eixos centrais do ensino de ciências, distintos, mas inter-relacionados (Flick, \& Lederman, 2006).

Particularmente no que se refere à Espanha, o currículo de ciências publicado em 2006, derivado da Ley Orgánica de Educación (LOE) ${ }^{1}$, é o primeiro a explicitar ações de investigação (Crujeiras-Pérez, 2014). A autora afirma que nos currículos anteriores havia referência à aprendizagem dos procedimentos da ciência e ao método científico, mas não eram explicitadas ações vinculadas à investigação (resolução de situações problema, identificação de variáveis, formulação de hipóteses, etc.). Além disso, cabe destacar a publicação, em 2007, de um número da revista Alambique - Didáctica de las Ciencias Experimentales, intitulado Enseñar y aprender investigando, que como consta em sua apresentação, "se centra en una de las opciones más interesantes y prometedoras para una actuación docente consistente con el conocimiento didáctico vigente: la posibilidad de enseñar y aprender ciencias investigando." (Cañal, 2007). Os artigos que compõem esse número da revista apresentam desde discussões teóricas sobre o assunto, incluindo, por exemplo, uma lista comentada de referências bibliográficas; até propostas escolares voltadas aos diferentes níveis de ensino e centradas em recursos didáticos variados, como webquest, feiras de ciências, experimentação, etc.

Quanto ao Brasil, a realização de investigações recebe destaque nos Parâmetros Curriculares Nacionais (PCN) e Orientações Complementares (PCN+). Nesses documentos, a investigação é entendida como um processo que permite o desenvolvimento de competências (Sá, 2009). Já nas atuais Diretrizes Curriculares Nacionais (MEC, 2013), a investigação vem associada a um princípio pedagógico, o da pesquisa, que, segundo esse documento, possibilita "que o estudante possa ser protagonista na investigação e na busca de respostas em um processo autônomo de (re)construção de conhecimentos.” (MEC, 2013, p.197). Na Base Nacional Comum Curricular (BNCC) do Ensino Fundamental publicada em 2017 a investigação ganha uma perspectiva epistemológica e social, com espaço relevante para a promoção de competências gerais que se associam à aprendizagem científica. Aparece no documento o papel da investigação como parte importante para "exercitar a curiosidade intelectual" mobilizando diferentes saberes para resolução dos problemas (MEC, 2017). Assim, a área de Ciências da Natureza busca assegurar "o acesso à diversidade de conhecimentos científicos produzidos ao longo da história, bem como a aproximação gradativa aos principais processos, práticas e procedimentos da investigação científica”. (MEC, 2017, p. 33). Nesse documento, portanto, é possível observar um interesse para a formação na perspectiva investigativa, em especial, no que se refere à competência específica da ciência, na qual os procedimentos da investigação científica são reconhecidos como práticas para promover o entendimento do mundo do aluno e que possibilitam "colaborar para a construção de uma sociedade justa, democrática e inclusiva”. (MEC, 2017, p. 36).

Cabe destacar que essas propostas e programas defendem a inserção de atividades

1 Trata-se da lei orgânica que regulamentou a educação básica (não universitária) na Espanha de 2006 até 2013 , quando foi substituída pela Ley para la mejora de la calidad educativa (LOMCE), vigente atualmente. 
investigativas nos currículos de ciências, mas não reconhecem essa abordagem enquanto perspectiva teórico-metodológica. Como menciona Sasseron (2015), em muitos contextos e trabalhos, as práticas investigativas são vistas como uma estratégia específica e não como uma abordagem didática, caracterizada por uma forma de agir coletiva, de trabalho conjunto de professor e estudantes, voltada à construção de entendimento sobre os conceitos, modelos e teorias da ciência e sobre a prática científica. Para essa autora o ENCI caracteriza-se como uma abordagem didática que deve ser compreendida como um arcabouço mais amplo que orienta as práticas pedagógicos e não, exclusivamente, como método de ensino-aprendizagem.

Além disso, ao longo desses anos, ocorreram várias mudanças nos objetivos, abordagens e sentidos atribuídos às atividades investigativas. Por exemplo, atualmente, é criticada a realização de atividades investigativas com a intenção de os alunos vivenciarem o método científico e há um consenso em torno da necessidade de superarmos a visão de ciência neutra e orientada por um método infalível. Para Rodrigues e Borges (2008) essa história é permeada por distintos "estilos de pensamento" (Fleck, 1979) que incluem o desenvolvimento pessoal dos indivíduos, preocupações com o desenvolvimento econômico das nações, com a construção de uma imagem mais sofisticada sobre a ciência e a investigação científica e com o desenvolvimento de habilidades necessárias para a solução de problemas da vida cotidiana (atuais e futuros).

Munford e Lima (2007) também reconhecem que há diferentes perspectivas e afirmam que todas buscam uma maior aproximação entre a ciência que é ensinada na escola e a que é praticada nos centros de pesquisa. Para essas autoras, o que caracteriza essas propostas é "um modo de trazer para a escola aspectos inerentes à prática dos cientistas" (Munford, \& Lima; 2007, p. 6) e, com isso, superar um ensino centrado em “(...) proposições científicas, apresentadas na forma de definições, leis e princípios e tomados como verdades de fato, sem maior problematização e sem que se promova um diálogo mais estreito entre teorias e evidências do mundo real." (Munford, \& Lima; 2007, p. 2). Diante dessa preocupação, o trabalho chama atenção para cuidados que se deve ter ao desenvolver as atividades, em especial para que não contribuam para a construção de uma imagem deformada da atividade científica. Os autores discutem que é preciso ter clareza sobre as semelhanças e diferenças que existem entre uma atividade investigativa desenvolvida na escola e a que é realizada pelos cientistas; segundo os autores, além de contextos e recursos diferentes, as primeiras possuem como finalidade promover a aprendizagem de um conhecimento já consolidado, enquanto as segundas intencionam produzir novos conhecimentos. Associado a isso, entendem como equivocados os que compreendem que as atividades investigativas envolvem, necessariamente, atividades experimentais e abertas e que, por meio delas é possível ensinar todo e qualquer conteúdo.

Ou seja, há uma multiplicidade de sentidos atribuídos às atividades investigativas no ensino de ciências. Contudo, entendemos os pressupostos do ENCI como determinantes para o reconhecimento dessas atividades como práticas reflexivas e culturalmente contextualizadas. Diante disso, explicitamos que este trabalho entende 
essas atividades como centrais para a formação de cidadãos conscientes e aptos a tomar posição frente ao mundo (Freire, 2005) e, assim como Trópia (2015), defendemos que elas devem:

[...] ir além das atividades técnicas instrumentalistas, como coleta e análise de dados, discutindo relações e implicações sociais e políticas da investigação científica na sociedade com a inclusão das controvérsias e possíveis limites da Ciência durante a realização das atividades. (Trópia, 2015, p.57).

Para isso, éimportante reconhecer que as atividades investigativas não se reduzem a práticas de experimentação/laboratório. Situações que envolvem problemas do cotidiano, questões sociocientíficas ou socioambientais também carecem de investigações para serem compreendidas. Nessa perspectiva, a investigação se transforma em um processo no qual a produção, a comunicação e a avaliação do conhecimento interagem de forma complexa e com vista à resolução/explicação de um problema socialmente relevante, na linha do que é defendido no âmbito do ENCI e nos trabalhos de Trópia (2015) e de Jimenéz-Aleixandre (a exemplo de Crujeiras, Jiménez Aleixandre e Gallastegui (2013) e de Reigosay e Jiménez Aleixandre (2000)).

\section{Procedimentos Metodológicos}

Para alcançar o objetivo desta investigação - caracterizar aspectos formativos e visões de ciências presentes em produções centradas em atividades investigativas e publicadas em periódicos da área de ensino de ciências do Brasil e Espanha - realizamos uma revisão sistemática da literatura da referida área. Esse tipo de investigação caracteriza-se por focar em uma questão bem definida e identificar, selecionar, avaliar e sintetizar conhecimentos disponíveis sobre a mesma (Azevedo, \& Scarpa; 2017; Galvão, \& Pereira, 2014;).

Considerando a representatividade que possuem na comunidade científica, as seguintes revistas foram selecionadas para análise: Enseñanza de las Ciencias, Revista Eletronica de Enseñanza de las Ciencias, Revista Eureka, Alambique - Didáctica de las Ciencias Experimentales, Didáctica de las ciencias experimentales y sociales, Ciência \& Educação, Investigações em Ensino de Ciências, Revista Ensaio Pesquisa em Educação em Ciências, Revista Brasileira de Pesquisa em Educação de Ciências e Alexandria: Revista de Educação em Ciência e Tecnologia.

Certamente, essa amostra de revistas não esgota o universo de pesquisas sobre essa temática; nem é esta a pretensão deste levantamento. Apesar disso, entendemos que ela é suficiente para as intenções desta pesquisa pois, possivelmente, a ampliação da amostra não levaria a uma categorização/análise distinta da realizada, relacionada aos objetivos formativos e visões de ciências explícitos ou implícitos nos estudos da área. Também, cabe destacar que, neste momento, não pretendemos conclusões em termos quantitativos; ou seja, nossa intenção não é investigar o que predomina, mas, sim, o que comparece. Num segundo momento, com uma ampliação da amostra, poderão ser traçadas considerações de ordem quantitativa e discussões sobre tendências 
predominantes na pesquisa em ensino de ciências.

Nos sistemas de busca dessas revistas, procuramos pela palavra investigação em português, espanhol e inglês. Em seguida, e considerando que os termos podem estar presentes nos artigos, mas esses não serem voltados à realização de atividades investigativas, realizamos uma busca nos arquivos dos artigos selecionados na etapa anterior. Para isso, considerando que os arquivos estavam em formato PDF, usamos o sistema de busca do Adobe Acrobat Reader DC, procurando pelas palavras indagación (nos artigos em espanhol) e investigação (nos artigos em português). Com isso, foi possível constatar se o artigo mencionava os termos no âmbito da realização de atividades investigativas ou em outros contextos. Nesse momento, também observamos a nacionalidade dos autores dos trabalhos e a época da publicação, mantendo somente trabalhos de autores espanhóis e brasileiros publicados entre 2010 e 2015, ou seja, nos últimos seis anos que antecedem essa pesquisa. Cabe destacar que optamos por não fazer distinções entre os artigos em função das perspectivas de ensino implicadas, ou seja, não diferenciamos entre os fundamentados no ENCI e os que abordam atividades investigativas sem uma definição clara da perspectiva em que se inserem. Isso foi feito justamente porque pretendemos compreender os objetivos formativos e visões de ciências independente da fundamentação teórico-metodológica assumida pelos autores.

Além disso, definimos que a análise seria desenvolvida nos moldes da Análise Textual Discursiva (ATD) (Moraes, \& Galiazzi, 2007), que corresponde à análise de dados e informações de natureza qualitativa, desenvolvida com a finalidade de produzir novas compreensões sobre os fenômenos e discursos investigados. Essa metodologia foi escolhida por que possibilita a reconstrução dos textos de forma a ampliar seus significados, especialmente no que diz respeito aos discursos implícitos. Além disso, ela permite categorias emergentes e não excludentes, como pretendido nesta investigação.

Diante disso, foram desenvolvidas as três etapas da ATD: (1) desconstrução e unitarização dos materiais textuais da análise; (2) formação de novas estruturas de compreensão dos fenômenos sob investigação e, (3) descrição e interpretação dos resultados e a produção de metatextos. Na primeira etapa ocorreu a desconstrução dos textos na perspectiva de identificar e destacar, no corpus, enunciados de interesse. Para isso, elaboramos um instrumento composto pelos seguintes itens: objetivos do trabalho; contexto ou nível de ensino a que se refere; finalidades atribuídas às atividades; tema/ assunto/conteúdo abordado (em caso de apresentar alguma atividade); dinâmica sugerida/utilizada para a realização das atividades; principais resultados e considerações. Os enunciados, que são frases, parágrafos ou partes maiores dos textos relacionadas a esses itens, foram, na segunda etapa, reunidos em grupos que abarcam elementos comuns. Nessa etapa "emergiram" as categorias, que representam o ponto de partida para a produção, sob a forma de metatextos, das descrições e interpretações possibilitadas pela análise, terceiro momento da investigação. Cabe destacar que a validade e confiabilidade da análise foram garantidas por meio do rigor empregado na realização de cada uma dessas etapas; também, os resultados são ancorados na realidade empírica, ou seja, em 
excertos do corpus analisado, seguindo o recomendado pelos idealizadores da ATD.

\section{Caracterização geral dos trabalhos analisados}

A partir da seleção do corpus foram levantados 41 artigos, distribuídos conforme Tabela 1. Nessa distribuição, percebe-se que as produções sobre o assunto estão aumentando na Espanha e no Brasil; passando de nenhuma produção no ano de 2010 a 10 e 8 artigos em 2015, respectivamente. Isso pode indicar que se trata de uma temática de pesquisa emergente, apesar de defendida há longa data, como discutido anteriormente.

Tabela 1. Distribuição de artigos por revista por ano

\begin{tabular}{lccccccc}
\hline Revista & $\mathbf{2 0 1 0}$ & $\mathbf{2 0 1 1}$ & $\mathbf{2 0 1 2}$ & $\mathbf{2 0 1 3}$ & $\mathbf{2 0 1 4}$ & $\mathbf{2 0 1 5}$ & $\begin{array}{c}\text { Total de } \\
\text { artigos }\end{array}$ \\
\hline Enseñanza de las Ciencias & 0 & 0 & 0 & 2 & 2 & 2 & 6 \\
\hline $\begin{array}{l}\text { Revista Eletronica de } \\
\text { Enseñanza de las Ciencias }\end{array}$ & 0 & 0 & 0 & 0 & 0 & 0 & 0 \\
\hline Revista Eureka & 0 & 0 & 1 & 0 & 1 & 5 & 7 \\
\hline $\begin{array}{l}\text { Alambique - Didáctica de las } \\
\text { Ciencias Experimentales }\end{array}$ & 0 & 1 & 2 & 3 & 3 & 3 & 12 \\
\hline $\begin{array}{l}\text { Didáctica de las ciencias } \\
\text { experimentales y sociales }\end{array}$ & 0 & 0 & 0 & 0 & 2 & 0 & 2 \\
\hline Total Espanha & $\mathbf{0}$ & $\mathbf{1}$ & $\mathbf{3}$ & $\mathbf{5}$ & $\mathbf{8}$ & $\mathbf{1 0}$ & $\mathbf{2 7}$ \\
\hline Ciência \& Educação & 0 & 0 & 1 & 0 & 0 & 2 & 3 \\
\hline $\begin{array}{l}\text { Investigaçães em Ensino de } \\
\text { Ciências }\end{array}$ & 0 & 0 & 2 & 0 & 1 & 1 & 4 \\
\hline $\begin{array}{l}\text { Revista Ensaio Pesquisa em } \\
\text { Educação em Ciências }\end{array}$ & 0 & 0 & 0 & 0 & 0 & 3 & 3 \\
\hline $\begin{array}{l}\text { Revista Brasileira de Pesquisa } \\
\text { em Educação em Ciências }\end{array}$ & 0 & 1 & 0 & 0 & 0 & 0 & 1 \\
\hline $\begin{array}{l}\text { Alexandria: Revista de } \\
\text { Educação em Ciência e } \\
\text { Tecnologia }\end{array}$ & 0 & 0 & 0 & 0 & 1 & 2 & 3 \\
\hline $\begin{array}{l}\text { Total Brasil } \\
\text { TOTAL }\end{array}$ & $\mathbf{0}$ & $\mathbf{1}$ & $\mathbf{3}$ & $\mathbf{0}$ & $\mathbf{2}$ & $\mathbf{8}$ & $\mathbf{1 4}$ \\
\hline
\end{tabular}

A amostra analisada é composta de trabalhos com distintos objetivos de pesquisa. Há estudos centrados na apresentação de propostas de ensino (a exemplo de T5, T10, T25, T26, TIII e TXII²) e outros se voltam à análise da implementação de uma atividade ou sequência de aulas junto aos alunos com a intenção de verificar/refletir sobre suas contribuições formativas, sob diferentes aspectos (como é o caso de T2, T19, T23, TI e TVIII). Também, foram encontrados trabalhos preocupados com os processos avaliativos, centrados em apresentar um instrumento/matriz de competências para

2 Os artigos espanhóis estão representados pelos números arábicos enquanto os artigos brasileiros pelos números romanos. A relação de trabalhos encontra-se no final deste artigo. 
avaliar os alunos quando desenvolvem atividades investigativas (a exemplo de T1, T27, TV e TVI) ou em debater questões investigativas a serem utilizadas em avaliações ou ações para sala de aula (como T3, TII e TXIII).

As pesquisas apresentam uma preocupação direta com a sala de aula e com o desenvolvimento de propostas. $\mathrm{Na}$ Espanha não foram encontrados trabalhos estritamente teóricos, nem que centram suas análises nos espaços curriculares para desenvolver atividades de investigação (análise de livros didáticos, documentos oficiais, etc.) e/ou que visam conhecer as compreensões de professores sobre esse enfoque ou sobre a construção/natureza da ciência. No Brasil essas preocupações aparecem de modo mais sistemático. Nesse caso, as discussões visam estabelecer um panorama acerca do conhecimento científico e das especificidades das áreas que o compõe. Discussões de cunho social e relacionadas à participação crítica no mundo também aparecem nesses trabalhos, mas, de modo disperso e sem aprofundamentos. Além disso, as ações e as articulações possíveis entre os objetivos educacionais almejados e as propostas investigativas desenvolvidas, não são apresentadas de modo claro.

Sobre o contexto educacional em que os trabalhos estão centrados ou foram desenvolvidos, há trabalhos com alunos da educação básica (como T3, T8, T16, TII, TIV e TXII) e com professores em formação (a exemplo de T7, T14, T20, TI, TVIII e TXI). Merece destaque o fato de não haver no caso da Espanha, na amostra selecionada, trabalhos que investigam alunos dos anos iniciais da educação básica (primária ou infantil); mas, este nível de ensino comparece em pesquisas relacionadas à formação de professores, indicando que há uma preocupação nesse sentido. No caso da amostra brasileira, atividades investigativas para os anos iniciais são mais proeminentes e foram encontradas, por exemplo, em TIII e TV. Associado a isso, é importante reconhecer as características das revistas investigadas, que estão mais voltadas à educação básica e, também, o fato das pesquisas da área de didática das ciências experimentais, de um modo geral, estarem mais direcionadas à educação básica e formação de professores.

Os principais resultados e considerações apontados pelos artigos analisados referem-se: às potencialidades das atividades para a formação dos alunos; às dificuldades enfrentadas pelos alunos; aos desafios de ordem curricular e relacionados à formação dos professores. Destacamos que no caso Espanhol, como muitos trabalhos são propostas de ensino, os autores apontam esses resultados sem apresentar uma análise sistemática de dados, ou seja, as discussões são construídas considerando suas percepções sobre a implementação das propostas apresentadas, em especial, os publicados na revista Alambique, em virtude das características desse periódico, que está centrado na divulgação de propostas didáticas e/ou relatos de experiência. No caso brasileiro, os trabalhos propõem, implementam e analisam os resultados de modo a articular as ideias do que se poderia reconhecer como uma atividade de investigação com os desafios que surgem à medida que tais ações são tratadas nos contextos reais de sala de aula. Quando se trata de estudos de aula, comparecem discussões sobre a coleta e análise de dados e, em geral, são utilizadas respostas dos alunos a questionários de avaliação, registros 
escritos elaborados pelos pesquisadores e/ou gravações em vídeo realizadas durante a implementação das atividades investigativas.

Sobre as potencialidades, os estudos afirmam que os alunos se interessam por atividades baseadas em investigações, desenvolvem habilidades investigativas, aprendem conceitos e modelos científicos, constroem uma visão mais crítica sobre a ciência e sobre os cientistas, percebem a importância da ciência para a compreensão e solução de problemas do mundo real. Além disso, para TXI, os movimentos discursivos do professor possuem papel fundamental para o desenvolvimento e efetividade das atividades investigativas visto que pode promover o engajamento de alunos diante dos problemas enfrentados nesse processo de ensino-aprendizagem. Nesse tipo de trabalho, entendemos que há aproximações aos pressupostos do ENCI, pois são construídas propostas e reflexões que conjugam a aprendizagem do conhecimento científico nas atividades investigativas com dimensões que o permeiam, como a produção do conhecimento e os contextos sociais e culturais que cercam a vida do estudante.

Com relação às dificuldades enfrentadas, esses estudos destacam a ausência de conhecimentos científicos e de habilidades investigativas por parte dos alunos o que impede, muitas vezes, que eles consigam planejar uma atividade de investigação e desenvolvê-la de forma autônoma e exitosa; também, que consigam aplicar o conhecimento teórico a uma situação contextualizada, relacionada ao cotidiano. Diante disso, apontam que os alunos precisam ser auxiliados de alguma maneira e/ou que as atividades devem ser realizadas de forma progressiva. A título de exemplificação, destaca-se T19 que coloca que esse auxílio pode ser do próprio professor, e deve ocorrer, principalmente, para que os alunos utilizem o conhecimento científico que possuem para elaborar a investigação e/ou para explicar situações do cotidiano. Segundo os autores, isso é necessário porque muitos alunos entendem que para resolver os problemas não são necessários conhecimentos conceituais, mas, somente, habilidades procedimentais. T22 sugere a utilização de andaimes linguísticos, como o diálogo entre os alunos e a escrita, por meio do preenchimento de fichas sobre as atividades. T27, por sua vez, conclui que as atividades precisam ser realizadas de forma progressiva, com níveis de autonomia distintos e definidos a partir dos conhecimentos e habilidades que os alunos já possuem. Nesse contexto, ganha força a importância de se conhecer os conhecimentos prévios dos alunos e, mais do que isso, as habilidades que eles possuem.

Quanto aos desafios, os artigos apontam que trabalhar com essa abordagem exige tempo e, diante disso, criticam os currículos extensos, entendidos como empecilhos para a implementação dessas atividades. Também, afirmam que é preciso investir na formação de professores, visto que eles são centrais para o sucesso das atividades e apresentam dificuldades semelhantes às enfrentadas pelos alunos. Nesse sentido, destacamos T14 que aponta que os professores em formação inicial, apesar de apresentarem interesse por atividades de investigação, possuem dificuldades para estruturar sequências didáticas coerentes com o ENCI, propor questionamentos aos alunos e estabelecer conclusões que levem a sínteses dos conceitos abordados. Por outro lado, T20 afirma que apesar de 
os professores conseguirem reconhecer as etapas que compõem uma investigação, eles têm dificuldade para estabelecer ações concretas, coerentes com cada uma dessas etapas, o que pode estar associado às suas compreensões sobre a construção do conhecimento científico. TVII, fazendo coro aos problemas levantados, aponta a necessidade do diálogo constante na formação inicial e continuada de professores, o que pode ocorrer por meio de espaços de debate em grupos de pesquisa que possibilitam o suporte para ações dos docentes. Nessa linha, defende atividades investigativas menos centradas nos conceitos científicos e articula tais ações para o desenvolvimento da habilidade cognitiva dos alunos. Para TXIV a relação estabelecida entre o conhecimento científico e o contexto social é outro desafio a ser enfrentado pelos professores quando atividades investigativas visam promover uma visão crítica da ciência aos estudantes.

\section{Objetivos formativos e visões de ciências}

Na sequência, discutimos os objetivos formativos e visões de ciências emergentes da análise dos artigos.

\section{Objetivos formativos}

Reconstruções históricas da educação científica, a exemplo das realizadas por Krasilchick (1987), indicam que diferentes finalidades educacionais têm guiado o ensino de ciências. Nesse universo de propósitos, merecem destaque os voltados à formação de cientistas, de uma elite "culta", de trabalhadores e de cidadãos críticos e atuantes. Os mesmos têm sido influenciados pelas políticas públicas, pelos anseios da sociedade e do Estado, por ideias educacionais mais amplas e por pesquisas da área. Em resumo, essas diferentes perspectivas educacionais buscam aumentar a participação dos alunos no processo de aquisição dos conhecimentos; desenvolver uma maneira científica de pensar e agir; motivar os alunos; contextualizar do conhecimento científico escolar; discutir as implicações sociais/ambientais do desenvolvimento científico e tecnológico, etc. Além disso, no universo de estudos que discutem a polissemia das atividades investigativas e do ENCI, são destacados vários objetivos formativos, como apresentado anteriormente.

Tomando por base essa diversidade de perspectivas e, ao mesmo tempo, considerando os artigos analisados, entendemos que as atividades investigativas podem ser associadas a três perspectivas distintas, mas que se articulam, quais sejam: (i) aprender ciências e/ou sobre ciências; (ii) desenvolver atitudes científicas; (iii) compreender e participar do mundo contemporâneo. Em alguns casos, portanto, o foco está em ensinar os alunos a investigar (propriamente dito) e em outros, a investigação é vista como um meio para outros aprendizados. Como discutido a seguir, todos esses objetivos podem ser associados a discursos formativos críticos e ingênuos; sendo que visões mais críticas trazem importantes contribuições para a formação dos alunos. É importante esclarecer que um mesmo artigo pode apresentar objetivos diferentes, indicando que há uma pluralidade de perspectivas associadas.

$\mathrm{Na}$ perspectiva aprender ciências e/ou sobre ciências a ênfase das atividades de 
investigação está na aprendizagem de conhecimentos relacionados à ciência, sejam conceitos ou modelos científicos ou aspectos da construção desses conceitos ou modelos. Também, nessa perspectiva enquadram-se os que buscam motivar os alunos ou aumentar seu interesse pelas ciências visto que por trás dessa preocupação está a aprendizagem dos conceitos científicos. Certamente, aprender ciências é um dos objetivos da educação científica, porém, é importante que esse aprendizado não se limite à esfera conceitual e à motivação. Nesse sentido, é importante destacar que na maioria desses trabalhos há uma preocupação com a contextualização do conhecimento, mas esse não é o foco. As aproximações com o contexto comparecem como um meio para facilitar a aprendizagem dos conceitos científicos escolares.

A seguir encontram-se alguns excertos de artigos que apresentam essa preocupação:

En este trabajo se describe el diseño e implementación de una actividad de indagación guiada, contextualizada en la salud, para enseñar las disoluciones reguladoras de $\mathrm{pH}$ a alumnos de bachillerato, y se analiza el aprendizaje de los estudiantes. (T15)

En primer lugar pretendemos suscitar el interés del alumna-do por la química, y que considere la posibilidad de escogerla en $4 .^{\circ}$ de ESO (e incluso en bachillerato y en la universidad). (T9)

O problema escolhido, o "problema da cestinha", tem como objetivo levar o aluno a compreender a relação entre a altura de lançamento de uma bolinha e seu alcance ao sair de uma rampa. (TV)

A atividade envolveu quatro aulas geminadas duas a duas. Nas duas primeiras, foi construído o conceito de densidade. Nas duas seguintes, focalizadas na análise que aqui apresentamos, o objetivo foi promover a compreensão da relação entre densidade e a flutuação de objetos em determinado meio. (TIX)

No caso de desenvolver atitudes científicas as atividades são realizadas na perspectiva de contribuir para o desenvolvimento de habilidades de investigação, compreendidas como imprescindíveis tanto para a formação de cientistas quanto para a vida em sociedade. Ainda que sejam abordados conhecimentos científicos e que algumas dessas atividades estejam contextualizadas na história ou no cotidiano dos alunos, a ênfase está nas habilidades desenvolvidas, a exemplo de: identificar o problema, elaborar hipóteses, planejar um procedimento experimental, elaborar conclusões, etc. A preocupação com o desenvolvimento de habilidades investigativas em alguns casos, associa-se à manipulação de instrumentos para a coleta de dados ou à capacidade de seguir um roteiro já estabelecido; em outros, de forma mais crítica, associa-se à capacidade de reconhecer problemas, de se distanciar dos fenômenos, e de buscar meios para compreendê-los e solucioná-los. Vale destacar o cuidado que devemos ter ao enfatizar este propósito, visto que a educação básica não tem a função de formar cientistas e que, muitas vezes, essa preocupação com as atitudes científicas pode 
ser associada à essa intenção, como foi no passado. Os excertos a seguir explicitam essa preocupação, presente em alguns artigos.

El proyecto C33 de ECBI que desarrollamos en el centro educativo tiene por objetivo hacer que el alumnado conozca la naturaleza del conocimiento científico, desarrolle habilidades científicas (sacar conclusiones de datos, diseñar experimentos...) y adquiera el hábito y actitud de posicionarse cientificamente ante los fenómenos. (T25)

En este artículo se propone la participación del alumnado en las prácticas científicas - producir, evaluar y comunicar conocimientos -como un enfoque adecuado para favorecer el aprendizaje sobre la naturaleza de la ciencia. (T10)

Entendemos que o ensino por investigação pode providenciar aos alunos o acesso às práticas da ciência, de forma a aproximá-los da natureza da ciência e promover sua alfabetização científica. (TVIII)

Admitimos que os alunos podem construir significados acerca dos conceitos científicos, desenvolver habilidades procedimentais investigativas. Concordamos com Campos e Nigro (1999) que o ensino como investigação, não é formar cientistas, mas pessoas que pensam sobre os fenômenos de modo não superficial. Os autores citados apresentam argumentos favoráveis associados ao ensino de ciências como investigação. (TIV)

Por fim, na perspectiva compreender e participar do mundo contemporâneo comparece uma preocupação com situações-problema reais. A ênfase deixa de estar nos conceitos científicos, nas habilidades ou na natureza da ciência, que são entendidos como meios para compreender uma situação mais ampla pertencente à realidade dos alunos. Nesse caso, passam a receber destaque problemas e temáticas relacionadas às questões ambientais, econômicas e políticas; alguns desses polêmicos e controversos envolvem discussões morais e éticas. Os excertos a seguir exemplificam essa perspectiva:

Se describe una propuesta de actividades diseñada con la clara intencionalidad de concienciar sobre las repercusiones que tiene en el medio ambiente la producción y distribución de los alimentos que consumimos habitualmente. El planteamiento y resolución de problemas socioambientales en un contexto real, mediante actividades orientadas a la indagación, favorece la implicación del alumnado en las actividades, además de incrementar su comprensión de nuestras responsabilidades en la generación de los problemas y sus soluciones. (T5)

En cuanto a la imagen, las actividades están contextualizadas en la vida real, son problemas de los llamados auténticos. El propósito es favorecer el desarrollo de una imagen de la química como un conocimiento útil para la vida. (T9)

(...) foi possível trabalhar conceitos científicos, de modo a conduzir os estudantes a uma reaproximação do objeto de estudo de forma reflexiva, uma vez que a aprendizagem do conhecimento científico seria necessária para compreensão da realidade em torno de um problema local do Rio Cachoeira. (TXII) 
Nesse caso, destaca-se o cuidado que se deve ter para não cair em propostas reducionistas, que deixam os conhecimentos científicos de lado, e se baseiam em opiniões pessoais ou presentes na mídia. Também, para não recair em visões ingênuas, entende-se que é preciso reconhecer que o posicionamento com base em conhecimentos científicos não é suficiente. Como apontado por várias pesquisas (Guimarães; Carvalho, \& Oliveira, 2010; Jiménez-Aleixandre; Agraso, \& Eireixas, 2004; Simonneaux, \& Simonneaux, 2009), outros fatores influenciam o processo de tomada de decisão, a exemplo das questões econômicas, políticas, dos valores assumidos pelos sujeitos e de aspectos afetivos.

Ainda no que diz respeito aos objetivos formativos, embora haja uma preocupação com o aprendizado de conceitos e o desenvolvimento de atitudes científicas, a maioria das atividades mencionadas nos artigos não parte de conceitos, mas da discussão de fenômenos do dia-a-dia ou de problemas relacionados ao contexto em que vivem os alunos. Isso corrobora as recomendações para o ensino de ciências, que enfatizam que esse deve ser desenvolvido de forma contextualizada.

Particularmente no que diz respeito aos problemas e conceitos centrais das atividades, encontramos três grupos, relacionados a (i) modelos/conceitos da ciência, (ii) fenômenos do dia-a-dia e (iii) problemas em contexto. As atividades centradas em conceitos científicos investigam questões relacionadas ao conceito de calor e aos processos de transferência de energia, tectônica de placas, modelos atômicos, evolução biológica, misturas e soluções, unidades e medidas, química inorgânica, estrutura celular, respiração e fotossíntese, dentre outros. Nesse caso, o foco está no modelo científico e não no fenômeno ou fato; esse, quando presente, não passa de um cenário para a discussão daquele. Exemplos de atividades que contemplam essa preocupação podem ser encontradas em T2, T6, T21, TXI e TXIII. Por outro lado, o grupo dos Fenômenos abarca as atividades sobre geração espontânea; propriedades dos materiais e mudança de estado; movimento da Terra e do Sol. Essa preocupação pode ser encontrada, por exemplo, em T8, T23, TVIII e TX. Por fim, há atividades centradas em problemas próximos do cotidiano ou contexto dos alunos, presentes, por exemplo, nos trabalhos T5, T7, T10, TI, TIII, TVII e TXIV. Como exemplos de atividades desse tipo, destacam-se as que propõem investigar qual a melhor pasta de dente, porque há diferentes preços de presunto espanhol (jamón), situações da realidade da comunidade local, reflexões sobre o ser e a sociedade, relações entre a biodiversidade e a vida no planeta (consequências da introdução de uma espécie de peixes em um lago), qual detergente é mais eficaz, dentre outros.

Quanto às potencialidades das atividades investigativas, segundo Caamaño (2012), as centradas em problemas teóricos (conceituais) seriam as mais apropriadas quando o objetivo está associado ao aprendizado de modelos científicos. Por outro lado, as atividades voltadas para problemas práticos (fenômenos do dia a dia e problemas em contexto), seriam recomendadas quando o objetivo se centra na compreensão dos processos da ciência. Interessante perceber que na amostra analisada não é possível estabelecer um padrão entre os objetivos formativos e problemas/conceitos abordados 
nas atividades. Há artigos que objetivam o aprendizado de conceitos científicos e estão centrados em problemas práticos, apesar de Caamaño (2012) destacar que os problemas teóricos são essenciais para a elaboração de modelos científicos escolares. Assim, destacamos que ainda que se tenha certo consenso acerca da necessidade de se atrelar o conhecimento a ser tratado com reflexões teóricas, é importante reconhecer a complexidade de construir tais relações. Essa demanda comparece nos trabalhos analisados, por vezes, quando se busca um entrelaçamento entre as preocupações associadas à perspectiva crítica ou na superação do ensino tradicional, contudo, esbarrase nos currículos e estruturas escolares que objetivam outras demandas ao ensino de ciências que não dialogam com os objetivos das atividades investigativas.

\section{Visões de ciências}

No que se refere às visões de ciência, a partir da análise propomos três ênfases distintas, mas complementares, associadas a reconhecer que (i) há ações que caracterizam a atividade científica; (ii) a ciência é influenciada pelo contexto; (iii) o conhecimento científico é relevante, mas insuficiente para compreender e resolver todos os problemas da humanidade. A proposta de análise das três ênfases não reflete uma tentativa de exclusão de um olhar ou outro sobre as atividades propostas, mas de trazer um panorama geral acerca de qual visão de ciência está sendo privilegiada quando se propõe as atividades investigativas.

Nesse sentido, debates sobre visões de ciências já foram largamente tratadas na área de ensino (Gil-Pérez, et. al., 2002). Ideias apresentadas por professores e pesquisadores em ensino de ciências como visões a-históricas ou a concepção rígida de um método científico (Gil-Pérez, et. al., 2001) são, em muitos casos, pensamentos que permeiam tanto o processo de pensar sobre como se constitui o processo de fazer ciências quanto de ensiná-la. Por esse motivo, ao se pensar sobre visões de ciência, pretende-se trazer um debate sobre os modos como estão sendo negociados os sentidos atribuídos à ciência nas atividades investigativas, ao mesmo tempo em que se busca compreender em que medida essas percepções se aproximam da visão do ENCI, que prioriza o olhar para a ciência como uma construção humana e também reconhece seus aspectos sociais e culturais.

Em geral, os trabalhos em ENCI refletem uma preocupação com a superação das visões deformadas sobre o conhecimento científico e seus processos de produção. No contexto das pesquisas envolvendo atividades investigativas alguns trabalhos também trazem tal reflexão pelo reconhecimento de sua potencialidade em dar suporte para que os alunos compreendam o processo do fazer científico, assim como, sua possibilidade de construir ações que superem os saberes ditos de senso comum.

A ênfase dada à realização de determinadas etapas ao longo da investigação pode contribuir para que os alunos reconheçam que há ações (bem definidas) que caracterizam a atividade científica e que são importantes para diferenciar um conhecimento científico de um não científico (a-científico ou pseudocientífico). Enquadram-se nessa categoria 
os trabalhos que enfatizam as etapas a serem seguidas no processo de investigação, a exemplo de TIV que aponta o desenvolvimento das atividades investigativas partindo de um problema inicial, levantamento de hipóteses, exposição de ideias prévias dos alunos, exposição e consciência do que pensam, proposição de atividades e experimentos através da observação, registro, análise de dados e conclusão. T11 também chama atenção para as etapas de uma investigação e destaca que independente do problema a ser investigado (prático ou teórico), as etapas a serem seguidas são: análise do problema, planejamento do método de resolução, realização do (s) experimento (s), avaliação do resultado e comunicação.

Além desses artigos, os excertos a seguir exemplificam como essa ênfase nas ações que caracterizam a atividade científica comparece nos artigos analisados.

Nessa proposta, as atividades são organizadas com foco em problema e envolvem etapas da investigação científica, tais como: proposição de um problema em torno de um objeto ou fenômeno natural; formulação de hipóteses; realização da atividade experimental; discussões das observações e conclusões; e o registro de toda a atividade. (TIII)

Conforme argumenta Laburú (2003), o objetivo não é um cientista. Eles representam papéis distintos. Poderíamos dizer que fazer ciência é distinto de entender e aprender ciências, que é principalmente distinto de aprender algo sobre a ciência, caso comum das salas de aula. (TIV)

Em síntese, as atividades relatadas nos artigos são organizadas a partir de diferentes etapas. Uma articulação de todas as propostas analisadas nos leva à seguinte estrutura: identificação/reconhecimento do problema, elaboração de hipóteses, planejamento e realização de investigações para comprovar as hipóteses, análise dos resultados e elaboração de explicações com base em conhecimentos científicos, elaboração de conclusões e socialização dos resultados. Dessa análise destacamos que a socialização de resultados não tem recebido destaque nas atividades, assim como a elaboração de hipóteses, de conclusões e reflexões sobre o processo realizado. Em geral, a ênfase está na observação do fenômeno e na identificação/reconhecimento do problema; na realização de investigações (experimentos, observação ou pesquisas) e na análise dos resultados e elaboração de explicações com base em conhecimentos científicos.

Nesse caso, é preciso atentar para não passar a ideia de que a atividade de investigação desenvolvida com os alunos é um retrato das atividades realizadas pelos cientistas, deixando de considerar a complexidade intrínseca a ela e os processos de transposição didática. Também, a preocupação com a linearidade do processo pode levar à compreensão de que existe um método científico único e infalível que conduzirá, sempre, à verdade. Em poucos artigos, como é o caso de T14 e T26, comparece uma discussão nesse sentido, ou seja, que destaca a complexidade e a dificuldade em caracterizar uma atividade de investigação. Os excertos a seguir, retirados de T14 e T26, retratam essa preocupação:

Es sabido que no es fácil estabelecer una lista de procesos que permita realizar una 
descripción de un contexto de indagación. (...) Podemos inferir que un análisis de un contexto de aula implica el estúdio de una gran variedad de aspectos que en conjunto expresarían la complejidad del proceso. (...) En consecuencia, podemos deducir que existiendo unos elementos claves que definirían qué es una actividad indagación (resolución de situaciones problemáticas para el alumno y progresso en la autorregulación del aprendizaje), el modelo se plantea lo suficientemente flexible como para contemplar la variabilidad de situaciones didácticas. (T14)

Los distintos pasos de la investigación (observación, análisis, conclusión,...) se interelacionan entre sí en un proceso en espiral que no tiene, realmente, ningún inicio ni final definidos, y puede recorrer itinerários diversos sujetos a la creatividad y no por ello incorrectos científicamente. (T26)

Esses autores dialogam com a literatura em ensino de ciências, pois enfatizam a importância do reconhecimento da ciência como parte de um processo em constante mudança, com níveis hierárquicos que se sobrepõem para elaborar modelos capazes de dar suporte aos diferentes fatores intrínsecos aos problemas científicos que precisam ser respondidos (Pozo, \& Crespo, 2009).

Em alguns artigos pesquisados é expressa a possibilidade de se voltar às etapas anteriores, revê-las e realizá-las novamente com uma perspectiva distinta. Por exemplo, caso o experimento não tenha contribuído para comprovar a hipótese, deve-se planejar um novo procedimento. O corpus representativo desse grupo, portanto, procura dar suporte às limitações das atividades investigativas como momentos importantes para questionar os métodos e elaborar concepções de ciência como uma elaboração reflexiva constante, tanto do ponto de vista experimental quanto conceitual.

Além disso, nesses trabalhos, no que se refere às reflexões sobre o processo, tem sido enfatizada a importância de contribuir para que os alunos percebam que a ciência é uma atividade humana; que os cientistas compartilham alguns pressupostos, mas são pessoas diferentes, com distintas inteligências e essas influenciam a maneira de trabalhar. Associado a isso, que o conhecimento científico é provisório e está relacionado a demandas da sociedade. Os artigos analisados que enfatizam esses aspectos pertencem à segunda visão de ciência, articulado à ideia de que a ciência é influenciada pelo contexto e, em função disso, permite diferentes interpretações sobre os fenômenos.

Essa visão, em geral, está presente em atividades que discutem o que influenciou as decisões tomadas pelos integrantes dos grupos em cada etapa, o fato de os grupos terem realizados procedimentos diferentes e/ou terem encontrado resultados distintos, etc. Como exemplos, destacamos os excertos a seguir:

Mediante debates en el aula se llega a un conocimiento compartido entendido como un consenso que permite la realización colaborativa de la actividad. (T4)

Además de estas dimensiones más relacionadas con la experimentación en el laboratorio, los estudiantes participan en las prácticas científicas asociadas con la producción, comunicación y evaluación del conocimiento, aprendiendo otras dimensiones más 
generales. Algunos ejemplos son: el carácter social de la toma de decisiones en la producción del conocimiento; la relevancia no sólo de las discusiones en el pequeño grupo, sino también de la puesta en común de distintos diseños; la relevancia de evaluar el conocimiento, tanto en la justificación de las decisiones tomadas como en la evaluación de los diseños experimentales propuestos por los demás grupos, y del consenso entre toda la classe para poner en práctica el más apropiado;(...). (T10)

O conceito de prática epistêmica associa-se, assim, a uma mudança de sujeito epistêmico, que passa de um conhecedor individual para uma comunidade de prática. Nessa perspectiva, no contexto escolar, o foco analítico afasta-se de uma consciência individual e volta-se para o processo social de investigação, em que são valorizadas as interações discursivas entre alunos e professor e de alunos entre si quando estes se envolvem na construção e na legitimação de conhecimentos. (TIX)

Os resultados desta pesquisa apontam que é possível trabalhar com atividades investigativas, tanto com alunos de pouca idade como maiores, utilizando-se, para isso, estratégias adequadas a cada faixa etária. Para os professores, a escolha de estratégia didáticas foi um desafio para que as atividades investigativas se aproximassem dos modelos de aprendizagem participativa. (TI)

Discussões dessa natureza podem contribuir para ressaltar que os cientistas são influenciados por fatores externos - pessoais, sociais, políticos e econômicos - e levar à construção de uma visão mais ampla e realista sobre ciência.

Além disso, alguns trabalhos enfatizam a ideia de colaboração no processo de ensino-aprendizagem, reconhecendo que as práticas investigativas são parte de uma interação constante entre diferentes atores escolares. Isso pode contribuir para que a ciência seja percebida como um conhecimento construído e aprendido de modo participativo. Nesse caso, destacamos o trabalho T26 que explicita, dentre outras, as seguintes características das atividades de investigação:

La ciencia como constructo social. Existen eventos de comunicación informal y negociación social de modelos científicos en varios formatos en el que participa, también... la capacidad de convicción de sus participantes o las presiones sociales. Las múltiples organizaciones sociales del aula significan una aportación a esta concepción. La ciencia es una aventura cognitiva. No existe una "solución correcta" que se pueda consultar para comparar si la nuestra lo es. Sólo "procesos correctos", "explicaciones razonables" y "consensos de la comunidad". Este último es un punto importante, ya que enseñar al alumnado a gestionar la incertidumbre (distinguir distintos grados de incertidumbre, tomar decisiones a partir de datos aproximados) es un aspecto fundamental en su educación científica. Por esa razón la actividad no ofrece la simulación a partir de la que se han generado las evidencias, ni una propuesta de "solución correcta". (T26)

Por fim, por meio de atividades investigativas pode-se contribuir para que os alunos reconheçam que o conhecimento científico é importante, mas não suficiente para compreendermos e resolvermos todos os problemas da humanidade. Em geral essa visão é possível quando são abordados problemas controversos, marcados por questões 
políticas, econômicas e culturais, e permeados por riscos e incertezas.

A título de exemplificação dessa categoria, destacamos os trabalhos a seguir:

Según Mayer (1998), los obstáculos para lograr que los estudiantes pasen de la mera preocupación por el medio ambiente a un compromisso real con su conservación están relacionados con planteamientos metodológicos centrados en la adquisición de conocimientos teóricos. El conocimiento sobre los problemas es necessário pero no suficiente para lograr una concienciación efectiva que produzca cambios en los comportamentos de los ciudadanos. (...) La educación desde la perspectiva de la sostenibilidad, como la que nosotros proponemos, está más guiada por nuestras emociones y valores que por los conocimientos. Por tanto, será necessário no solo ofrecer información, sino plantear situaciones que permitan reconstruir las conexiones entre el ser humano y el medio e integrar conocimientos, valores y emociones y comportamientos. (T5)

O ensino por investigação deve ir além das atividades técnicas instrumentalistas, como coleta e análise de dados, discutindo relações e implicações sociais e políticas da investigação científica na sociedade com a inclusão das controvérsias e possíveis limites da Ciência durante a realização das atividades. (TXIV)

Assim, a preocupação com o mundo vivenciado pelo aluno e sua relação com o saber científico ganham sentido quando pensados em diálogo com o contexto no qual vivem. Problematizar e refletir sobre o papel da ciência nesse mundo é parte dos objetivos das atividades de investigação que pretendem trazer para a escola questões potencialmente controversas. Além disso, essas atividades objetivam a construção de uma visão mais ampla da ciência, que inclui compreender a atividade científica enquanto prática epistêmica.

Ainda no que diz respeito às visões de ciência, as atividades investigativas mencionadas na maioria dos trabalhos analisados, centram-se na realização de alguma atividade experimental de laboratório. Também há trabalhos que sugerem a realização de investigações mais amplas, que não estão associadas a experimentos de laboratórios, mas a pesquisas de campo, na internet, livros, materiais elaborados pelos próprios professores, etc. Apenas um trabalho propôs uma atividade centrada na observação de um fenômeno, na linha demonstrativa, ou seja, na qual os alunos não colocavam a mão na massa, manipulando instrumentos ou coletando informações em fontes diversas. A partir desse resultado, retomamos a necessidade de superar a perspectiva - predominante nos trabalhos e também indicada em outros estudos da área - que compreende atividades investigativas como sinônimo de atividades experimentais/de laboratório. Essa atitude pode reforçar uma visão limitada sobre a prática científica e, por isso, é importante reconhecermos que o elemento central não está associado à realização do experimento em si, mas à busca de explicações para problemas, colocando em prática os conhecimentos construídos ao longo do processo de investigação. Essa questão tem sido amplamente discutida em trabalhos fundamentados no ENCI e que reconhecem que essa perspectiva contribui para a compreensão da atividade científica 
enquanto prática epistêmica, a exemplo de T9, T10, T19, T20 e TXIV.

Nessa linha, outro aspecto a destacar diz respeito à definição dos problemas e procedimentos de investigação. Em geral, essa tarefa é feita pelos professores, sem a participação dos alunos. Também, em alguns casos, o mesmo se sucede com a coleta de dados; ou seja, os alunos não realizam o procedimento experimental, eles recebem os dados prontos. Mas, isso não acontece com a análise dos dados, elaboração de explicações e de conclusões, que são realizadas pelos alunos com o auxílio dos professores. Diante disso, ressaltamos a necessidade de envolver os alunos em todas as etapas da investigação, em especial, para que eles possam perceber sua complexidade.

\section{Considerações Finais}

Este estudo foi desenvolvido com a intenção de compreender a pluralidade de sentidos atribuídos às atividades investigativas, almejando orientações que possam contribuir para a elaboração e desenvolvimento de práticas de sala de aula na perspectiva do ENCI. Para tanto, realizamos uma pesquisa de cunho bibliográfico, que apontou distintos objetivos formativos e visões de ciências associadas às atividades investigativas. Uma clareza com relação a essa diversidade é determinante para a construção de ações pedagógicas que sejam capazes de promover a reflexão e efetiva percepção dos problemas científicos em consonância aos problemas sociais que permeiam a vida dos alunos e professores. Por esse motivo, compreender como as atividades investigativas estão sendo tratadas nas pesquisas pode se tornar o primeiro nível analítico de um panorama para o reconhecimento dos entraves e potencialidades dessas atividades para a efetiva aprendizagem científica.

Desta análise destacamos que os objetivos formativos se voltam a aprender ciências ou sobre ciências, desenvolver atitudes científicas e/ou compreender e participar do mundo contemporâneo. Por outro lado, as visões de ciências associam-se a reconhecer que há ações que caracterizam a atividade científica, que a ciência é influenciada pelo contexto e/ou que o conhecimento científico é relevante, mas insuficiente para resolver todos os problemas da humanidade.

Dos resultados obtidos, reconhecemos que as aproximações entre as propostas de atividades investigativas apresentadas nos artigos analisados, tanto na Espanha como no Brasil, podem ser compreendidas pelas suas preocupações com a aprendizagem dos conteúdos científicos e da natureza da ciência. Os artigos de ambos os países trouxeram discussões que buscam apresentar e dar suporte para que alunos possam mobilizar conceitos científicos para responder aos desafios levantados durante as atividades. Ainda que não sejam maioria, esses trabalhos apresentam preocupações que, quando em consonância aos pressupostos do ENCI, indicam outras possibilidades de aproximação entre o mundo escolar e o mundo vivido, procurando dar condições aos estudantes para responder aos questionamentos cotidianos através da mobilização do saber científico.

Enquanto alguns trabalhos buscam delimitar espaços de atuação e congregar diferentes objetivos em torno das atividades investigativas em que o conteúdo da ciência 
é a prioridade a ser aprendida, outros, por sua vez, as argumentam como um instrumento potencialmente favorável para dar suporte a ações que visam o engajamento, a motivação, a busca de sentido no ato de aprender sobre ciências. A nosso ver, ambas perspectivas devem ser articuladas com a intenção de permitir a interação entre a produção, a comunicação e a avaliação do conhecimento com vista à resolução/explicação de um problema socialmente relevante.

De modo geral, ao passo que esses debates vão sendo tratados, percebe-se que existe uma dificuldade de articulação entre os objetivos pretendidos e as ações propostas. Em determinados momentos aparecem discursos mais reflexivos, que se inserem em diferentes esferas epistemológicas e sociais, mas as atividades desenvolvidas pouco contribuem para alcançar os objetivos almejados. Por exemplo, há discursos voltados à formação cidadã ou à busca de sentido para o que é realizado na escola, mas as ações restringem-se a atividades de laboratório, centradas em conceitos científicos e em cumprir um roteiro fechado. Nesse caso, defendemos a importância de reconhecer as dimensões pedagógicas discutidas neste trabalho e a necessidade de refletir sobre as relações entre os objetivos pretendidos e a natureza dos problemas investigados. Cabe apontar que as dimensões discutidas neste trabalho não devem ser tratadas em graus de significância. Ou seja, as práticas centradas na aprendizagem de conceitos não são inferiores às práticas que buscam a compreensão de mundo. Mas, devemos ter clareza acerca dos processos a serem enfrentados para cada proposta de atividade investigativa.

Além disso, este estudo aponta para a necessidade de realizarmos pesquisas nos anos iniciais e análises relacionadas às questões afetivas, axiológicas e sobre a linguagem, visto que não foram encontrados muitos trabalhos nessas linhas. Quanto a fovorecer uma melhor compreensão deste campo de pesquisas, destacamos a necessidade de ampliar a amostra tanto temporal quanto espacialmente, ou seja, selecionar outras revistas, de outros países, e um período maior. Com isso seria possível uma análise da evolução da área bem como uma sistematização das tendências e perspectivas em diferentes épocas.

\section{Agradecimentos}

As autoras agradecem à Fundação de Apoio à Pesquisa no Distrito Federal (FAPDF) pelo apoio financeiro ao projeto de pesquisa $\mathrm{n}^{\circ} 1062 / 2016$ - Edital $\mathrm{n}^{\circ}$ 03/2016 intitulado "Uma perspectiva crítica para o livro didático de ciências: atividades investigativas e narrativas na formação de professores de ciências".

\section{Referências}

Abd-el-Khalick, F., BouJaoude, S., Duschl, R., Lederman, N. G., Mamlok-Naaman, R., Hofstein, A., ..., \& Tuan, H. (2004). Inquiry in Science Education: International Perspectives. Science Education, 88(3), 397-419. https://doi.org/10.1002/sce.10118 
Anderson, R. D. (2002). Reforming Science Teaching: What Research says about Inquiry. Journal of Science Teacher Education, 13(1), 1-12. https://doi. org/10.1023/A:1015171124982

Andrade, G. T. B. (2011). Percursos históricos de ensino de ciências através de atividades investigativas. Ensaio: Pesquisa em Educação em Ciências, 13(1), 121-138. https://dx.doi. org/10.1590/1983-21172013130109. 38

Azevedo, N. H., \& Scarpa, D. L. (2017). Revisão Sistemática de Trabalhos sobre Concepções de Natureza da Ciência no Ensino de Ciências. Revista Brasileira de Pesquisa em Educação em Ciências, 17(2), 579-619. https://doi.org/10.28976/19842686rbpec2017172579

Barrow, L. H. (2006). A Brief History of Inquiry: From Dewey to Standards. Journal of Science Teacher Education, 17(3), 265-278. https://doi.org/10.1007/s10972-006-9008-5

MEC. (2013). Diretrizes Curriculares Nacionais Gerais da Educação Básica. Brasília: Secretaria de Educação Básica. Recuperado em 04 de julho de 2018, de http://portal. mec.gov.br/docman/julho-2013-pdf/13677-diretrizes-educacao-basica-2013-pdf/file

MEC (2017). Base Nacional Comum Curricular. Ensino Fundamental. Brasília: Secretaria de Educação Básica. Recuperado em 04 de julho de 2018, de http://basenacionalcomum. mec.gov.br/download-da-bncc

Caamaño, A. (2012). ¿Cómo introducir la indagación en el aula? Los trabajos prácticos investigativos. Alambique. Didáctica de las Ciencias Experimentales, 70, 83-91.

Cañal, P. (2007). La investigación escolar hoy. Alambique. Didáctica de las Ciencias Experimentales, 52, 9-19.

Couso, D. (2014). De la moda de "aprender indagando" a la indagación para modelizar: una reflexión crítica. In Actas del XXVI Encuentro de Didáctica de las Ciencias Experimentales. Huelva, Andalucía, España. Recuperado em 04 de julho de 2018, de http://www.apice-dce.com/actas/docs/conferencias/pdf/26ENCUENTRO_DCEConferenciaPlenariaInaugural.pdf

Crujeiras Pérez, B. (2014). Competencias e prácticas científicas no laboratorio de química: participación do alumnado de secundaria na indagación. (Tese de Doutorado). Universidade de Santiago de Compostela, Santiago de Compostela. Recuperado em 04 de julho de 2018, de http://hdl.handle.net/10347/12072

Crujeiras, B., Jiménez Aleixandre, M. P., \& Gallastegui, J. R. (2013). Indagación en el laboratorio de química. Secuencia de actividades en que el alumnado de $3 .^{\circ}$ y $4 .^{\circ}$ de ESO diseñan experimentos. Alambique. Didáctica de las Ciencias Experimentales, 74, 49-56.

Deboer, G. E. (2006). Historical Perspectives On Inquiry Teaching In Schools. In L.B. Flick, \& N. G. Lederman (Orgs), Scientific Inquiry and Nature of Science. Dordrecht: Springer. 
Fleck, L. (1979). Genesis and development of a scientific fact. Chicago: University of Chicago Press.

Flick, L. B., \& Lederman, N. G. (2006). Scientific Inquiry and Nature of Science. Dordrecht: Springer.

Freire, P. (2005). Pedagogia do Oprimido. Rio de Janeiro: Paz e Terra

Galvão, T. F, \& Pereira, M. G. (2014). Revisões sistemáticas da literatura: passos para sua elaboração. Epidemiologia e Serviços de Saúde, 23(1), 183-184. Recuperado em 04 de julho de 2018, de http://scielo.iec.gov.br/scielo.php?script=sci_arttext\&pid=S167949742014000100018\&lng=pt\&tlng=pt

Gil-Pérez, D., Montoro, I. F., Alís, J. C., Cachapuz, A., \& Praia, J. (2001). Para uma imagem não deformada do trabalho científico. Ciência \& Educação, 7(2), 125-153. https://dx.doi.org/10.1590/S1516-73132001000200001

Gil-Pérez, D., Cachapuz, A., \& Praia, J. (2002). A hipótese e a experiência científica em educação em ciência: contributos para a reorientação epistemológica. Ciência \& Educação, 8(2), 253-262. https://dx.doi.org/10.1590/S1516-73132002000200009. ca2.

Grandy, R., \& Duschl, R. (2007). Reconsidering the Character and Role of Inquiry in School Science: Analysis of a Conference. Science \& Education, 16(2), 141-166. https:// doi.org/10.1007/s11191-005-2865-z

Guimarães, M. A., Carvalho, W. L. P. de, \& Oliveira, M. S. (2010). Raciocínio moral na tomada de decisões em relação a questões sociocientíficas: o exemplo do melhoramento genético humano. Ciência \& Educação, 16(2), 465-477. https://dx.doi.org/10.1590/ S1516-73132010000200013

Hodson, D. (1994). Hacia un enfoque más crítico del trabajo de laboratorio. Enseñanza de las Ciencias, 12(3), 299-313. Recuperado em 04 de julho de 2018, de https://www. raco.cat/index.php/Ensenanza/article/view/21370

Jiménez-Aleixandre, M. P., Agraso, M., \& Eireixas, F. (2004). Scientific Authority and Empirical data in argument warrants about the Prestige oil spill. In Atas da Reunião Anual da National Association for Research in Science Teaching (NARST), Vancouver.

Krasilchik, M. (1987). Professor e o currículo das ciências. São Paulo: EPU/EDUSP.

Moraes, R., \& Galliazzi, M. do C. (2007). Análise Textual Discursiva. Ijuí: Editora Unijuí. Munford, D., \& Lima, M. E. C. C. (2007). Ensinar ciências por investigação: em quê estamos de acordo? Ensaio: Pesquisa em Educação em Ciências, 9(1), 89-111. https:// dx.doi.org/10.1590/1983-21172007090107.

NRC (2000). Inquiry and the National Science Education Standards: A Guide for Teaching and Learning. Washington: National Academy Press. 
NRC (1996). National Science Education Standards. Washington: National Academy Press.

Osborne, J., \& Dillon, J. (2008). Science Education in Europe: Critical Reflections. London: Nuffield Foundation. Recuperado em 04 de julho de 2018, de https://www. nuffieldfoundation.org/sites/default/files/Sci_Ed_in_Europe_Report_Final.pdf

Pozo, J. I., \& Crespo, M. A. (2009). A aprendizagem e o ensino de ciências. Do conhecimento cotidiano ao conhecimento científico. Porto Alegre: Artmed.

Reigosa, C., \& Jiménez Aleixandre, M. P. (2000). La cultura científica en la resolución de problemas en ellaboratorio. Enseñanza de las Ciencias, 18 (2), 275-284. Recuperado em 04 de julho de 2018, de https://ddd.uab.cat/pub/edlc/02124521v18n2/02124521v18n2p275. pdf

Reyes-Cárdenas, F., \& Padilla, K. (2012). La indagación y la enseñanza de las ciências. Educación Química, 23(4), 415-421. Recuperado em 04 de julho de 2018, de http:// www.scielo.org.mx/scielo.php?script=sci_arttext\&pid=S0187-893X2012000400002\&ln $\mathrm{g}=\mathrm{es} \&$ tlng=es

Rocard, M. (2007). Science Education Now: A Renewed Pedagogy for the Future of Europe. Brussels, Belgium. European Commissionea. Recuperado em 04 de julho de 2018, de http://ec.europa.eu/research/science-society/ document_library/pdf_06/report-rocardonscience- education_en.pdf (2.06.2015)

Rodrigues, B. A., \& Borges, A. T. (2008). O ensino de ciências por investigação: reconstrução histórica. In Atas do XI Encontro de Pesquisa em Ensino de Física (pp. 1-12), Curitiba, PR: Sociedade Brasileira de Física. Recuperado em 04 de julho de 2018, de http://www.sbf1.sbfisica.org.br/eventos/epef/xi/atas/listaresumos.htm

Sá, E. F. (2009). Discursos de professores sobre ensino de ciências por investigação. (Tese de Doutorado). Faculdade de Educação, Universidade Federal de Minas Gerais, Belo Horizonte, MG. Recuperado em 04 de julho de 2018, de http://www.bibliotecadigital. ufmg.br/dspace/bitstream/handle/1843/FAEC-84JQPM/2000000177.pdf? sequence=1

Sasseron, L. H. (2015). Alfabetização científica, ensino por investigação e argumentação: relações entre ciências da natureza e escola. Ensaio: Pesquisa em Educação em Ciências, 17(spe), 49-67. https://dx.doi.org/10.1590/1983-2117201517s04ov

Schwab, J. (1966). The Teaching of Science. Cambridge: Harvard University Press.

Simonneaux, L., \& Simonneaux, J. (2009). Students' socio-scientific reasoning on controversies from the viewpoint of education for sustainable development. Cultural Studies of Science Education, 4(3), 657-687. https://doi.org/10.1007/s11422-008-9141-x Trópia, G. (2015). A Relação Epistêmica com o Saber de Alunos no Ensino de Biologia por Atividades Investigativas. Alexandria: Revista de Educação em Ciência e Tecnologia, 8(3), 55-80. https://doi.org/10.5007/1982-5153.2015v8n3p55.ãia 
Zompero, A. F., \& Laburú, C.E. (2011). Atividades investigativas no ensino de ciências: aspectos históricos e diferentes abordagens. Ensaio: Pesquisa em Educação em Ciências, 13(3), 67-80. Recuperado em 04 de julho de 2018, de https://seer.ufmg.br/index.php/ ensaio/article/view/8545/6484

\section{Apêndice - Relação de trabalhos analisados}

1. Ferrés, C., Sanmartí, N., \& Marbà, A. (2015) ¿Cómo evaluar los trabajos de indagación del alumnado? Alambique Didáctica de las Ciencias Experimentales, 80, 1-10.

2. López-GayR, Jiménez Liso, M. R., \& Martínez Chico, M. (2015). Enseñanza de un modelo de energía mediante indagación y uso de sensores. Alambique Didáctica de las Ciencias Experimentales, 80, 38-48.

3. Goytia, E., Besson, I., Gasco, J., \& Domènech, J. (2015). Evaluar habilidades científicas. Indagación en los exámenes ¿Una vía para cambiar la práctica didáctica en el aula? Alambique Didáctica de las Ciencias Experimentales, 79, 1-11.

4. Jordi, D. (2014). Una secuencia didáctica en contexto sobre evolución, taxonomía y estratigrafía basada en la indagación y la comunicación científica. Alambique Didáctica de las Ciencias Experimentales, 78, 51-59.

5. Jaén, M., Esteve, P., \& Moreno, P. P. (2014). Indagar sobre la pérdida de biodiversidad desde el consumo alimentario ciudadano. Alambique Didáctica de las Ciencias Experimentales, 78, 43-50.

6. Solbes, J., \& Tuzón, P. (2014). Indagación y modelización del núcleo atómico y sus interaciones. Alambique Didáctica de las Ciencias Experimentales, 78, 34-42.

7. Cantó, J., Hurtado, A, \& Vilches, A. (2013). Educación científica más allá del aula. Una herramienta para la formación del profesorado en sostenibilidad. Alambique Didáctica de las Ciencias Experimentales, 74, 76-82.

8. Corominas, J. (2013). Actividades experimentales $\mathrm{POE}^{\star}$ en la enseñanza de la química y de la física. Alambique Didáctica de las Ciencias Experimentales, 74, 69-75.

9. Crujeiras, B., Jiménez Aleixandre, M. P., \& Gallástegui, J. R. (2013). Indagación en el laboratorio de química. Secuencia de actividades en que alumnado de $3 .^{\circ}$ y $4 .^{\circ}$ de ESO diseñan experimentos. Alambique Didáctica de las Ciencias Experimentales, 74, 49-56.

10. Crujeiras, B., Jiménez Aleixandre, M. P. (2012). Participar en las prácticas científicas. Aprender sobre la ciencia diseñando un experimento sobre pastas de dientes. Alambique Didáctica de las Ciencias Experimentales, 72, 12-19.

11. Caamaño, A. (2012). ¿Cómo introducir la indagación en el aula? Los trabajos prácticos investigativos. Alambique Didáctica de las Ciencias Experimentales, 70, 83-91.

12. Caamaño, A. (2011). Enseñar química mediante la contextualización, la indagación y la modelización. Alambique Didáctica de las Ciencias Experimentales, 69, 21-34. 
13. Martínez-Chico, M., López-Gay Lucio-Villegas, R., \& Jiménez Liso, M. R. (2014). ¿Es posible diseñar un programa formativo para enseñar ciencias por Indagación basada en Modelos en la formación inicial de maestros? Fundamentos, exigencias y aplicación. Didáctica de las Ciencias Experimentales e Sociales, 28, 153-173. https:// dx.doi.org/10.7203/DCES.28.3153

14. Aragüés, A., Gil Quílez, M. J., \& Gándara, M. (2014). Análisis del papel de los maestros en el desarrollo de actividades de indagación en el practicum de primaria. Didáctica de las Ciencias Experimentales e Sociales, 28, 135-151. https://dx.doi.org/10.7203/ DCES.28.3523

15. Tortosa Moreno, M. (2013). Aprendizage sobre disoluciones reguladoras de $\mathrm{Ph}$ mediante indagación guiada utilizando sensores. Enseñanza de las Ciências, 31(1), 189211.

16. Domènech Casal, J. (2013). Secuencias de apertura experimental y escritura de artículos en el laboratorio: un itinerário de mejora de los trabajos prácticos en el laboratório Enseñanza de las Ciências, 31(1), 249-262.

17. Pavón Martínez, F., \& Martínez Aznar, M. M. (2014). La metodología de resolución de problemas como investigación (MRPI): una propuesta indagativa para desarrollar la competencia científica en alumnos que cursan un programa de diversificación. Enseñanza de las Ciências, 32(3), 469-492. https://doi.org/10.5565/rev/ensciencias.1290

18. Martínez Chico, M., Jiménez Liso, M. R., \& López-Gay Lucio-Villegas, R. (2014). La indagación en las propuestas de formación inicial de maestros: análisis de entrevistas a los formadores de Didáctica de las Ciencias Experimentales. Enseñanza de las Ciências, 32(3), 591-608. http://dx.doi.org/10.5565/rev/ensciencias.1376

19. Crujeiras Pérez, B., \& Jiménez Aleixandre, M. P. (2015). Desafíos planteados por las atividades abiertas de indagación en el laboratorio: articulación de conocimientos teóricos y prácticos en las prácticas científicas. Enseñanza de las Ciências, 32(1), 63-84. http://dx.doi.org/10.5565/rev/ensciencias.1469

20. Vílchez González, J. M., \& Bravo Torija, B. (2015). Percepción del profesorado de ciencias de educación primaria en formación acerca de las etapas y acciones necesarias para realizar una indagación escolar. Enseñanza de las Ciências, 32(1), 185-202. http:// dx.doi.org/10.5565/rev/ensciencias.1529

21. Ezquerra Martínez, A., Iturrioz González, I., \& Díaz Pérez, M. (2012). Análisis experimental de magnitudes físicas a través de vídeos y su aplicación al aula. Revista Eureka sobre Enseñanza y Divulgación de las Ciencias, 9(2), 252-264. http://dx.doi. org/10.25267/Rev_Eureka_ensen_divulg_cienc.2012.v9.i2.07 
22. Domènech Casal, J. (2014). ¿Cómo lo medimos? Siete contextos de indagación para detectar y corregir concepciones erróneas sobre magnitudes y unidades. Revista Eureka sobre Enseñanza y Divulgación de las Ciencias, 11(3), 398-409. http://dx.doi. org/10.25267/Rev_Eureka_ensen_divulg_cienc.2014.v11.i3.09

23. Martínez-Chico, M., Jiménez Liso, M. R., \& López-Gay Lucio-Villegas, R. (2015). Efecto de un programa formativo para enseñar ciencias por indagación basada en modelos, en las concepciones didácticas de los futuros maestros. Revista Eureka sobre Enseñanza y Divulgación de las Ciencias, 12(1), 149-166. https://dx.doi.org/10498/16929

24. Marzo Mas, A., \& Monferrer Pons, L. (2015). Pregúntate, indaga y a la vez trabaja algunas competências. Revista Eureka sobre Enseñanza y Divulgación de las Ciencias, 12(1), 198-211. https://dx.doi.org/10498/16933

25. Domènech Casal, J. (2015). Eppur si muove: una secuencia contextualizada de indagación y comunicación científica sobre el sistema astronómico Sol-Tierra. Revista Eureka sobre Enseñanza y Divulgación de las Ciencias 12(2), 328-340. http://dx.doi. org/10.25267/Rev_Eureka_ensen_divulg_cienc.2015.v12.i2.07

26. Domènech Casal, J. (2015). Una secuencia didáctica de modelización, indagación y creación del conocimiento científico en torno a la deriva continental y la tectónica de placas. Revista Eureka sobre Enseñanza y Divulgación de las Ciencias, 12(1), 186-197. https://dx.doi.org/10498/16932

27. Ferrés Gurt, C., Marbà Tallada, A., \& Sanmartí Puig, N. (2015). Trabajos de indagación de los alumnos: instrumentos de evaluación e identificación de dificultades. Revista Eureka sobre Enseñanza y Divulgación de las Ciencias 12(1), 22-37. http://dx.doi. org/10498/16922

I. Gouw, A. M. S., Franzolin, F., \& Fejes, M. E. (2013). Desafios enfrentados por professores na implementação de atividades investigativas nas aulas de ciências. Ciência \& Educação, 19(2), 439-454. https://dx.doi.org/10.1590/S1516-73132013000200014

II. Torres, J., Almeida, A., \& Vasconcelos, C. (2015). Questionamento em manuais escolares: um estudo no âmbito das Ciências Naturais. Ciência \& Educação, 21(3), 655671. https://dx.doi.org/10.1590/1516-731320150030009

III. Solino, A. P., \& Gehlen, S. T. (2015). O papel da problematização freireana em aulas de ciências/física: articulações entre a abordagem temática freireana e o ensino de ciências por investigação. Ciência \& Educação, 21(4), 911-930. https://dx.doi.org/10.1590/1516731320150040008

IV. Zômpero, A. F., \& Laburú, C. E. (2012). Implementação de atividades investigativas na disciplina de ciências em escola pública: uma experiência didática. Investigações em Ensino de Ciências, 17(3), 675-684. 
V. Colombo Jr, P. D., Lourenço, A. B., Sasseron, L. H., \& Carvalho, A. M. (2012). Ensino de Física nos anos iniciais: análise da argumentação na resolução de uma "Atividade de Conhecimento Físico". Investigações em Ensino de Ciências, 17(2), 489-507.

VI. Solino, A. P., \& Gehlen, S. T. (2014). Abordagem temática freireana e o ensino de ciências por investigação: possíveis relações epistemológicas e pedagógicas. Investigações em Ensino de Ciências, 19(1), 141-162.

VII. Suart, R., Abras, C. M., Maculan, D. S., Pedroso, J. R., Rosa, L. M. R., Miranda, M. S., Bernardo, R. A., \& Marcondes, M. E. R. (2015). Uma análise do desenvolvimento de sequências de aulas por licenciadas de Química ao longo de um processo de reflexão orientada. Investigações em Ensino de Ciências, 20(2), 186-208. http://dx.doi. org/10.22600/1518-8795.ienci2016v20n2p186

VIII. Trivelato, S. L. F., \& Tonidandel, S. M. R. (2015). Ensino por investigação: eixos organizadores para sequencias de ensino de biologia. Ensaio: Pesquisa em Educação em Ciências, 17(spe), 97-114. https://dx.doi.org/10.1590/1983-2117201517s06

IX. Silva, A. C. T. (2015). Interações discursivas e práticas epistêmicas em sala de aula de ciências. Ensaio: Pesquisa em Educação em Ciências, 17(spe), 69-96. https://dx.doi. org/10.1590/1983-2117201517s05

X.Sasseron,L.H.(2015). Alfabetização científica, ensino por investigaçãoe argumentação: relações entre ciências da natureza e escola. Ensaio: Pesquisa em Educação em Ciências, 17(spe), 49-67. https://dx.doi.org/10.1590/1983-2117201517s04

XI. Silva, A. C. T., \& Mortimer, E. F. (2011). As estratégias enunciativas de uma professora de química e o engajamento disciplinar produtivo dos alunos em atividades investigativas. Revista Brasileira de Pesquisa em Educação em Ciências, 11(2), 117-138.

XII. Solino, A., \& Gehlen, S. (2014). A Conceituação Científica nas Relações Entre a Abordagem Temática Freireana e o Ensino de Ciências por Investigação. Alexandria: Revista de Educação em Ciência e Tecnologia, 7(1), 75-101.

XIII. Clement, L., Custódio, J., \& Alves Filho, J. (2015). Potencialidades do ensino por investigação para promoção da motivação autônoma na educação científica. Alexandria: Revista de Educação em Ciência e Tecnologia, 8(1), 101-129. https://doi. org/10.5007/1982-5153.2015v8n1p101

XIV. Trópia, G. (2015). A relação epistêmica com o saber de alunos no ensino de biologia por atividades investigativas. Alexandria: Revista de Educação em Ciência e Tecnologia, 8(3), 55-80. https://doi.org/10.5007/1982-5153.2015v8n3p55 


\section{Roseline Beatriz Strieder}
${ }^{1}$ http://orcid.org/0000-0001-8965-8906 Universidade de Brasília Instituto de Física Brasília, Distrito Federal, Brasil roseline@unb.br

Graciella Watanabe

${ }^{(0)}$ https://orcid.org/0000-0001-6710-0194 Universidade Federal do ABC Centro de Ciências Naturais e Humanas Santo André, São Paulo, Brasil graciella.watanabe@ufabc.edu.br

Submetido em 12 de Dezembro de 2017 Aceito em 13 de Julho de 2018 Publicado em 15 de Dezembro de 2018 